\title{
Rubrieke uit Namibië
}

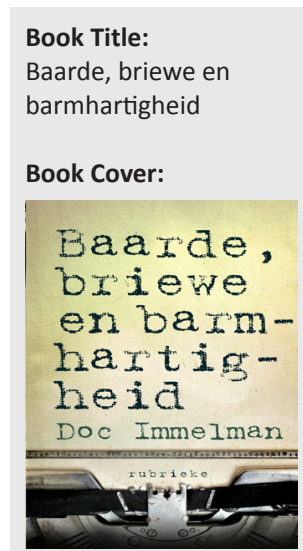

Author:

Doc Immelman

ISBN:

978-1-4853-001-3

Publisher:

Protea Boekhuis, Pretoria,

2013, 167 pp., ZAR130.00*

*Book price at time of review

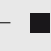

Review Title:

Rubrieke uit Namibië

Reviewer:

Cilliers van den Berg ${ }^{1}$

\section{Affiliation:}

${ }^{1}$ Department of Afrikaans and Dutch, German and

French, University of the

Free State, South Africa

Email:

vdbergjp@ufs.ac.za

\section{Postal address:}

PO Box 339, Bloemfontein

9300, South Africa

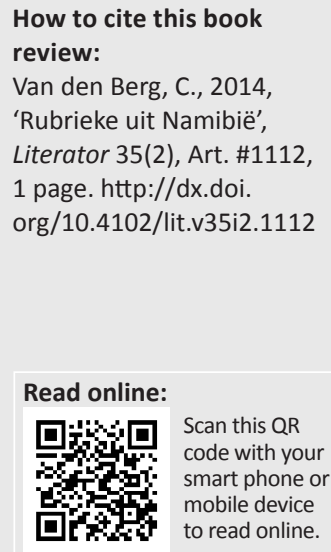

Met die afsterwe van Doc Immelman in Maart 2013 het die Afrikaanse ontspanningliteratuur een van sy mees produktiewe skrywers verloor. Veral bekend vir sy avontuurverhale, wat dikwels teen die agtergrond van Namibiese (of dan Suidwes-gegewe) vistas ontvou, het hy 'n allemintige getal publikasies die lig laat sien. Protea Boekhuis het 'n groot rol gespeel om heelwat van Immelman se tekste (11 altesaam) weer uit te gee en dit sodoende vir belangstellendes beskikbaar te stel. Een van hierdie werke is Baarde, briewe en barmhartigheid, 'n keuse van rubrieke wat indertyd in publikasies soos die Suidwes Afrikaner, Die Suidwester, Tempo en die Republikein verskyn het.

Eie aan die aard van die tipe rubriek wat in dagblaaie verskyn, is ook Immelman se bydraes by assosiasie verbonde aan die figuur (of is dit die gemoduleerde personasie?) van die outeur. Die keuse van onderwerpe wat onder die loep geneem word en die wyse waarop daar kommentaar gelewer word, is herleibaar tot die voorkeure en selfs 'geite' van die skrywer - iets wat gesoute bewonderaars natuurlik mettertyd goed leer ken. En by Immelman is dit dan ook nie anders nie: die rubrieke word deur 'n soms lakoniese, soms aweregse perspektief gestempel. Reeds die titel van die bundel dui die lakoniese aard van die 50 geselekteerde rubrieke aan, rubrieke wat oor 'n diverse verskeidenheid onderwerpe handel. Bevestig deur 'n voorwoord deur Willem Moore, word dit duidelik dat die skryfsels geen pretensie het buiten om vir 'n oomblik te vermaak, die leser dalk vir 'n minuut of twee oor iets te laat nadink nie: 'Skink gerus vir u 'n lekker koppie koffie of tee, sit terug en beleef Doc Immelman se tong in die kies omgang met totaal uiteenlopende onderwerpe $[\ldots]^{\prime}$.

So is daar staaltjies uit die verlede wat vertel word, daaglikse probleme wat aan bod gestel word, of gewoon die eienaardighede van mense in die algemeen wat beskryf word. Sommige van die geselekteerde stukke doen in nabetragting sekerlik naïef aan, gegewe die politieke konteks waarin baie van die stukke waarskynlik ontstaan het. Maar verrassend genoeg, is heelwat van hulle werklik humoristies en kan mens nie anders as om te glimlag nie. Om 'n besonder chauvinistiese voorbeeld te noem: In 'Raaisels' word gevra wat die verskil tussen 'n pessimis en 'n optimis is? Die antwoord: "n Pessimis dink alle meisies is sleg; 'n optimis hoop so'. Dit bring mens egter noodgedwonge terug na die stem van die outeur - en dit is duidelik die stereotipe van 'n tradisionele, ouer man wat selfs in een of twee rubrieke van 'julle jong outjies' praat. Eie voorkeure en voorwaardes tersyde gestel, kan mens egter moeilik anders as om heelparty van die stukke as suksesvol binne die parameters van die rubriek-medium te beoordeel - juis omdat hulle niks meer as dit wil wees nie.

Daarom word die rubrieke in 'n sekere sin ook 'n kuriositeit, deurdat dit 'n stem presenteer wat stories vertel en menings huldig vóór die inligtingsontploffing, maar ook algemene afplatting, wat die hedendaagse geglobaliseerde wêreld meegebring het. Nie dat alles uit die oude doos is nie, net dat hier (om self te stereotipeer) duidelik 'n ouer generasie aan die woord is. Wat op sy beurt beteken dat veral diegene met nostalgie vir die wêreld van toentertyd van Baarde, briewe en barmhartigheid sal hou. Andersyds is daar egter soveel van die stukke wat die gemeenplaas onderstreep: hoe meer dinge verander, hoe meer bly hulle dieselfde. Steeds is dit dikwels betreklik moeilik om gebruiksaanwysings te verstaan, steeds word mens ingeloop deur motorwerktuigkundiges en steeds kan die bewys van barmhartigheid tot jou eie nadeel strek.

Dit is nie 'n bundel met literêre waarde nie en die kwiksilwer vignette is dun gesaai. Maar in 'n skalkse oomblik, tydens die drink van 'n koppie koffie, kan 'n mens veel slegter vaar.

Copyright: (C 2014. The Authors. Licensee: AOSIS OpenJournals. This work is licensed under the Creative Commons Attribution License. 